\title{
Cross-border Migration in the Southern African Development Community (SADC): Benefits, Problems and Future prospects
}

\author{
Victor H. Mlambo \\ University of Zululand, Kwadlangzwa, South Africa \\ halavico@yahoo.com
}

\begin{abstract}
With rapid globalization sweeping through the globe, the movement of people throughout the world has increased significantly over the last 20 years. Motivated by the thrill of earning better salaries and living in countries characterised by better standards of living, people have travelled long distances in search of such opportunities. Undoubtedly, the economic buoyancy of countries like South Africa and Botswana has attracted thousands of migrants from the SADC who are seeking job opportunities, further straining government resources and impeding the effective functioning of border immigration services. The unequal rate of economic development in the region has further created an increasing gap between fast-developing and slow developing nations, hence the unequal rate of migration. Skills transfer and collaborations have been the major benefits of cross border-migration for SADC, although crime and xenophobia have also been identified as problems associated with cross-border migration in Southern Africa. The flow of remittances from South Africa has played a crucial role in fighting poverty and hunger in the migrant's home country and contributed significantly to government finances. However, the absence of a regionally accepted policy aimed at regulating migration means that illegal cross-border migration will carry on being a problem in the region and unfortunately the absence of policies aiming at spurring collective regional economic growth means illegal cross-border migration will increase in the years to come.
\end{abstract}

Keywords: Globalization, Economic Growth, Development, Policy, Migration

\section{Introduction}

Is it unquestionably clear that in an era characterised by rapid globalization, international and cross-border migration has become not only a beacon of hope for individuals and families seeking a better life, but it has also portrayed a growing economic divide between developing and developed countries. Many factors are in no doubt responsible for global migration, but ultimately the prospects of earning a better income and living in a country characterised by growth and political stability are the major reasons why people engage in migration. The growing economic inequalities between countries in the global North and South will undoubtedly be identified as a contributing factor in international migration for decades to come. Migration from developing regions such as Africa, Asia and South America to developed countries such as the United States, United Kingdom, Australia and Germany has reached alarming rates, often overwhelming the immigration and border services of these nations.This has, unfortunately, resulted in the tightening of borders, the implementation of stricter immigration policies and the overall change in criteria for admitting immigrants, even with these measures in place, migrants have persistently tried their best to circumvent them. While countries located in the global South are known to be characterised by poverty, malnutrition, corruption and political instability etc., contrary to popular belief, many in countries in this region attract a high number of migrants from neighbouring countries, partly due to the different characteristics (economic growth, job opportunities, education standards etc.), that makeup countries within the global South. In Asia, countries like China, Taiwan, Singapore, India and Malaysia attract a huge number of migrants from neighbouring countries, and in South America, Brazil, Argentina and Mexico also host a huge number of migrants from different countries in the region.

In Africa, migration is mostly concentrated between two regions namely West and Southern Africa. In West Africa, the economic hubs of Ghana, Nigeria and the Ivory Coast attract a huge number of migrants from neighbouring West African states, while in Southern Africa, South Africa, Botswana, Tanzania and Namibia are hosts to many migrants not only from the Southern African Development Community (SADC) but also from throughout Africa and beyond. SADC which is made up of 14states is characterised by a huge rate of inter-regional migration. Cross-border migration within the region is characterised by a combination of skilled and unskilled migrants, however, growing cross-border migration trends show that illegal migration is on the constant increase. The study will undoubtedly provide a critical review and current status quo 
regarding that state and rate at which cross-border migration is unfolding in Southern Africa. The study will also in detail ascertain whether cross-border migration in SADC has brought any benefits (knowledge transfer, increased financial flows, skills transfer) to member states. Undeniably, the European Union has been a motivating factor behind the increasing calls within Southern Africa to institute a coordinated policy to facilitate the free movement of people, considering the socio-economic benefits witnessed by the European Union as a result of constituting a regulated but free movement policy, the study then aim will at understanding the challenges associated with cross-border migration in Southern Africa and whether the EU model of free movement can be really instituted in the region. Furthermore, the study will explore the possibility as to whether member states can mutually agree on regulating cross-border migration and implementing policies would ensure member state benefit from such an agreement.

\section{Literature Review}

Migration within the SADC-An Overview: The quest for economic gain, improvement in the standard of living and an environment characterised by a better political climate has led to an increase in cross-border migration in the region (Odén, 1996). The goal of having a policy to ensure uninhibited movement within the region was further cemented by the development and adoption of the SADC protocol on free movement. This protocol was aimed at ensuring the uninhibited movement of people within SADC, while member states have approved the protocol, its applicability and functionality has been rather disappointing (Kok, 2006). The idea behind the formulation of the SADC was to model the European Union, where movement of people and goods is uninhibited, which is what has propelled the EU towards a steady developmental path since its inception (Saurombe, 2013). But because of trust and commitment factors within the SADC, these factors have somewhat thwarted the realisation and potential benefits that a free movementpolicy couldbringfor the region. The SADC has a long history of documented and adopted mechanisms which were solely developed to foster greater regional integration, but unlike the EU, member states were sceptical about their national interests being overridden by protocols of the regional body (Peters, 2010), hence till this day, regional integration in Southern Africa is somewhat flawed and not fully realised.

The Common Market for Eastern and Southern Africa (COMESA) protocol, which advocates for the free movement of labour, services and people has clearly not been fully implemented (Kok, 2006). One of the most important aspects of COMESA was the adoption of a visa-free policy, where citizens of member states would freely move within the region, while some countries in the region do not require visas when engaging in inter-regional travel (Plender, 1988), the adoption of a visa-free regime regionally has not been actually implemented. Furthermore; just like COMESA, the Migration Dialogue for Southern Africa (MIDSA), which was developed by the IOM in conjunction with the SADC has been really discouraging in terms of its implementation and proper functionality (Crush \& Dodson, 2017). The main aim of MIDSA was to foster regional cooperation on migration-related activities and through regular exchange and constant dialogue, however, the proposal was never really fully prioritized (Omelaniuk, 2012). Considering the vast amounts resources spread out between SADC member states, one would have hoped that cooperation would be at the forefront and highest level. Both COMESA and MIDSA were originally created to foster regional integration and growth, but their success has been questioned. While there is no denying that the economic buoyancy in countries like South Africa and Botswana has drawn a huge number of migrants from the region (Oucho, 2005), it is also evident that SADC has failed to collectively develop policies at aimed at stimulating economic growth in the region, hence the unequal rates of migration.

While Southern Africa is characterised by a huge movement of people from border to border, cross-border migration is not equal in the region (Bastia, 2013). The unequal rate of economic growth in the region has been identified as one of the major contributors to cross-border migration in SADC. For example, the GDP of South Africa is larger than all of the remaining 13 member countries (Godsäter, 2016); hence forging equal and inclusive economic growth in the region becomes extremely difficult. Unfortunately, according to Chen (2016), the unequal rate of economic development has also contributed to brain drain and resulted in brain gain for some member states. Semi-industrialised or fast-growing countries have the ability to attract skills from other countries and with the prospect of living a better life characterised by financial freedom (Nshimbi \& Moyo, 2017), many SADC member states lose a considerable number of skilled professionals to other member states (Oderth, 2002). The major beneficiaries of these skills have been South Africa and Botswana, 
however, it is worth to note that not all migrants engaging in cross-border migration are skilled professionals Mattes et al. (2000), the region experiences one of the highest inter-regional migration of unskilled migrants (Zuberi et al., 2016). Williams (2002) opines that the easy accessibility of migrants as a source of cheap labour mostly in sectors such as agriculture, construction and mining negatively affects any attempts to regularise the stay of migrants, let alone upholding and protecting their rights. Cross-border migration in the region is not a new phenomenon, long before the 1990's, the discovery of gold in South Africa ushered in a new wave of migration to the country, and by 1970, there were over 260000 male labour migrants working in South African mines (Gasa, 2007). SADC is a region characterised by primary labour-intensive industries such as mining, and agriculture, and coupled with the unequal rate development in the region, these industries usually attract a huge number of migrants (Lippoldt, 2012).

While cross-border migration can be managed more effectively in the region, the problem is that policies aimed at managing cross-border migration have to align with the interests of individual member states, which at times can be cumbersome to achieve (Willimans\& Crush, 2005). Fast developing countries in the bloc are characterised by growing economies, sound infrastructure and higher GDP's and hence they are seen as been able to handle a large sum of illegal migrants compared to countries with opposite characteristics (Obeng, 2010), and this perhaps may be one the reasons why some member states have been reluctant to support the idea of a visa-free regime in the region. Magidimisha (2018) alludes that another reason why SADC members have not reaped the full rewards that are associated with migration is that some member states have come to the conclusion that only a few countries are actually enjoying the benefits of migration in the region and hence while some countries are gaining skills, some are directly witnessing the opposite.

For Jalilian (2012) cross-border migration regardless of whether it is undertaken legally or illegally, has numerous benefits for both the sender and receiving country, cross-border migration brings skills, knowledge and innovation which may not be available at the country of destination, in turn, migrants work and send money back home, resulting in increased regional financial flows. Crush (2017) argues that crossborder migration has been beneficial to some extent, migrants in South Africa are involved many entrepreneurial ventures such as motor repair businesses, barbershops and they employ South Africans, contributing indispensably in the transfer of skills and knowledge. Crush \& Dodson (2017) state that regulating migration will not bring any substantial changes in SADC in terms of migration trends as the unequal socio-economic conditions will continue being the major drivers of cross-border migration in the region. This implies that regulating cross-border migration may be impossible, however, a policy, which will be regionally accepted and implemented not to regulate migration, but rather to guide the region when dealing with cross-border migration-related issues may be ideal. Magidimisha et al. (2018) further state that while cross-border migration may result in increased regional remittance flows in Southern Africa, however, remittances alone cannot be viewed as a justifiable variable to encourage cross-border migration especially because some countries lose valuable skills and human capital in the process.

Mapuva \& Muyengwa-Mapuva (2014) state that economically developed countries within Southern Africa have not collectively encouraged regional economic growth, through increased investments and trade, rather countries have prioritised their own development. Nshimbi \& Moyo (2017) in their analysis, opine that because most migrant's cross-bordersin search of economic opportunities, SADC states should urgently prioritise regional economic development and integration. Powell \& Powell (2016) however, realise that achieving equal rates of economic growth in the region would be virtually impossible as some countries have a competitive advantage over others in terms of manufacturing, industrialization and economic development, and while achieving equal rates of economic growth may reduce cross-border migration, it will not stop it all together as the migrationprocess is motivated by different socio-economic factors. DeTemple (2007) floats the idea of implementing a free trade policy asa tool to fight cross-border migration. The author states that SADC countries are characterised by the fast availability of resources, and if these resources can be regionally traded without duties, customs or tariffs, they would contribute effectively to the development of member states, hence providing economic opportunities for locals.

Keating (2004) agrees with the above statement, however, states that fully realising the benefits of a free trade policy might take decades, and in the meantime, SADC will continue witnessing increasing rates of cross-border migration. It is also worth to note that not all member states in the region equally benefit or are 
negatively affected by cross-border migration; hence reaching a regionally accepted policy in managing crossbordermigrationmight be burdensome. Markowitz (2017) opines that regional countries have prioritised international trade rather than regional trade; hence many SADC trade markets are tapped by other countries rather than regional states. Peters (2010) states that the SADC is characterised by an increasing rate of economic inequality, hence with such a scenario, cross-border migration characterisedby the need for economic freedom ultimately becomes the major motivating factor. There are unquestionably many factors responsible for the ever increasing rate of cross-border migration regionally, and many authors have counterargued on whether there are any benefits that memberstates can accrue from cross-border migration, however, the increase in regional remittance flows can be viewed as a positive development, especiallyina region where more than 60 million were reportedlyliving in extreme poverty in 2010 (Brynard, 2011).

Determinants of cross-border migration in SADC: Push factors: Undeniably, the main challenge facing the SADC is how to collectively channel resources in order to properly manage cross-border migration. Economic migrants are by far the most types of people that engage in cross-border migration in the region (Peters, 2010). Unfortunately, because of the inequalities in terms of economic development, people will definitely continue engaging in cross-border migration for years to come. With no proper management policies aimed at regulating migration in the region, some countries will continue receiving a huge number of migrants. Cross-border migration is influenced by many underlying factors, commonly these factors are known as push and pull, the paper seeks to discuss the major push factors responsible for cross-border migration in Southern African.

Push factors influencing cross-border migration in SADC-Economic disparity: Undoubtedly, economic inequality in the region is the major motivating factor encouraging people to engage in cross-border migration. The ever growing economic divide in terms of economic growth, development and job opportunities has contributed to the increase in cross-border migration regionally (Human Rights Watch, 1998). The existence of a growing economic disparity among SADC member states will undeniably make the provision of effective cooperation rather difficult. Wisner et al. (2005) opine that the GDP of South Africa is largest in the bloc; hence South Africa may feel that its interests need to be considered first, further hampering and obstructing efforts made at achieving regional economic growth and development in the region. Crush \& Dodson (2017) opine that a clear and all-inclusive mechanism is needed that would contribute to economic growth in all member states, however, because countries have their individual interest, some member states may opt not to agree to a comprehensive deal on economic growth not only because they may feel it will erode their national interests, but also because they may feel that fast-growing economies may benefit more from such arrangements (International Organization for Migration, 2006). The ever growing rural and urban unemployment in Southern Africa has led to a substantial increase in individualsattempting to crossborders in search of economic openings. Nshimbi\&Moyo (2017) mention that the unwillingness or perhaps inability of SADC countries to jointly develop and implement regional economicinitiatives will remain the major obstruction in the bloc'saim to reduce cross-border migration, the authors conclude by stating that to reduce cross-border migration, SADC states should internally implement policies to spur economic growth, failure to do this will surely result many skilled nationals leaving and looking for opportunities elsewhere, further contributing to the ever-increasing problem of braindrainin Southern Africa. Lucas (2005) states that for the SADC to reduce cross-border migration, robust and pragmatic polices are needed which would be characterised by rapid human development, infrastructure provision and the availability and easy access to health and educational institutions. However, with sluggish economic growth regionally, it is unlikelythat Southern Africa willsuddenly witness a boom in economic development. It is therefore highly observable that economic development is the key in reducing crossborder migration in SADC, but regrettably, with growth being difficult to achieve currently, the increase in cross-border migration is highly probable going forward. Economic migration is rife in the region, with South Africa being the most preferred hub, therefore with the continuous divide in the region, cross-border migration will likely continue into the foreseeable future.

Employment opportunities and Educational opportunities: Boampong (2014) states that a report by the world economic forum found that as a result of unemployment, more than 27 million young people have crossed borders in search of employmentopportunities. Bradshaw \& Ndegwa (2000) state that illegal crossborder migration is problematic and increasing rapidly in Southern Africa, however, skilled labour migration 
can be very beneficial for the region as migrants may return with new skillsand knowledge, hence contributing to the growth of their home countries. Crush \& Dodson (2017) allude that the SADC should harmonize Sub-regional migration polices as to increase the flow of goods, services and trade as this will encourage cross-borderinvestment. Solé et al. (2016) mention that most individuals engaging in cross-border migration within the SADC are low skilled and illegal migrants, hence regulating migration would be futile as these individualsareusually employed in the informalsector or are self-employed and usually migrate in large numbers.Economic inequality has a direct nexus with the unemployment rate, because of economic inequality; countries in the region cannot sustain effective economic growth, hence increasing the rate of jobless people (Andersen \&Lindsnaes, 2007). Economically developing countries, therefore, host a huge number of skilled and unskilled migrants who are purely there for economic reasons. In South Africa, skilled migrants from the region are mostly concentrated in the health, science and higher education sectors, while unskilled migrants focus on informal trading, spaza shops, mechanic workshops and barbershops (International Organization for Migration, 2008). Ever since the deterioration of the economic situation in Zimbabwe in the early 2000's, more than 300000 jobs seeking Zimbabweans have flocked to South Africa in search of a better life, making it the biggest contributor of migrants in the country (Van Rensburg, 2016).

Wellman \& Landau (2015) mention that most migrants in South Africa are mostly economic migrants, motivated by the prospects of higher income, therefore; migrants travel long distances to reach the country. Leerkes (2009) states that illegal cross-border migration has been associated with an increase in crime, drug peddling and the straining of government resources. MelusiGigaba, the former Minister of Home Affairs in South Africa mentioned that is while illegal migration is on the increase in the SADC, it is neither possible nor desirable to slow down international migration (Cox, 2016). Therefore, it is clear that in the absence of a regionally accepted policy managing and regulating cross-border migration, people will in no doubt carry on engaging in illegal migration. While cross-border migration relating to education is mostly legal, it has been identified as another contributing factor behind migration in the region (Lemarchand \& Schneegans, 2014). The demand for quality education has resulted in many young enthusiastic individuals opting to cross borders in search of education (Speckman \& Mandew, 2014). Within the regional bloc, South Africa undoubtedly attracts the bulk of potential students from SADC not only because of the world-class universities that are located in the country but also because of the SADC protocol which states that five percent of South Africa's higher education places should be reserved for students from member states (Hahn, 2005). Halvorsen \& Vale (2016) state that students in the region opined that they were likely to opt to study in South Africa because it was closer to home, it has the potential to secure them a job and some simply valued the culture of the country, while students from the USA and Europe stated that the low cost of living was the main reason they had come to study in South Africa.

SADC students have been known for being one of the most mobile groups in the globe. Wohlmuth et al. (2014) state that cross-border migration as a result of education is good for the region as it results in millions of dollars in inter-regional financial flows, however, not all countries in the region equally benefit from these financial flows. The nexus between the above-mentioned push factors is that they are all linked to economic growth and development, therefore, implying that if the economies of SADC member states improved drastically, all these push factors can be addressed with relevant investments in the economy. The SADC is characterised by different economic situations, hence push factors that encourage cross-border migration in the region are not same in terms of their prevalence in member countries, and that is why the region experiences unequal rates of cross-border migration

Cross-border migration and its benefits for the SADC: Not all has been doom and gloom in terms of crossborder migration in the region. In fact, cross-border migration has been a success for other countries which are characterised by a chronic shortage of skills; however, the failure of cross-border migration to equally benefit every member state has been one of the issues hampering the developing and adoption of a collective agreement regulating the free movement of people in the region.

Increase in Remittance flows: Schiantarelli (2005) states that as a result of the increase in both illegal and legal cross-border migration in Southern Africa, the region has been constantly witnessing an increase in the flow of remittances. According to data from the Centre for Financial Regulation and Inclusion (2012) remittances outflow from South Africa to SADC amount to R11.2bn per yearly, Leonard (2013) further states 
that with unemployment and HIV rife in the region, the remittances sent home by migrants from South Africa undoubtedly play a huge role fighting poverty and hunger. Zimbabwe has the largest share of remittances sent from South Africa, this is justifiable considering the number of Zimbabweans living and working in South Africa.The World Bank estimates that in 2014, remittance flows within the SADC reached a staggering \$1bn (Crush \& Dodson, 2017). Beaton et al. (2017) further opine that remittances in the region have been a huge contributor to the income earned by foreign governments, as they have steadily contributed to the operating budget of SADC countries. Grinin et al. (2016) mention that while remittances flow in the region are forever on the increase, greater economic equality is needed to further consolidate regional cooperation and development. The increase in remittance flows regionally are a positivedevelopment, however increasing remittance flows cannot be used a pretext to encourage cross-border migration in the region, mainly because they are not equally distributed and do not contribute to human capital development andeconomic growth compared to the provision and availability of skilled professionals ina country. It is certainlyclear that regardless of the role played by remittances in SADC, as the rate of cross-border migration increases, so will they.

Skills provision and Education expertise: Cross-border migration in SADC has proved to be a lifeline for countries suffering from brain drain like South Africa which has seen a huge number of its skilled professionals leave the country (Pécoud \& Guchteneire, 2007). Immediately after 1994, South Africa witnessed a huge number of skilled professionals leave the country (mainly whites) which left a void in the country. Fortunately for the county, many skilled foreign nationals from SADC and beyond have migrated to South Africa and surely filled that void. The higher education, health and engineering sectors have been immense beneficiaries of skills from the SADC (International Organization for Migration, 2008), which goes to show that cross-border migration has benefited some states in the region. South Africa has been aided by its sound infrastructure and economy in it being able to attract skills from beyond the country's borders. Other countries such as Botswana and Namibia have also attracted a huge number of skilled professionals from the region, thanks to their growing economies. The mass inter-regional migration of skills from the SADC is a consequence of the ever-growing unequal rates of growth in the region and further portrays the will of migrants to travel great distances to reach their preferred destinations (Matlosa, 2001). While the SADC has a protocol which stipulates that member states shall not poach skilled professionals from other SADC countries, it has been largely poorly enforced and furthermore the will of migrants themselves coupled with skills shortages within the region makes it difficult for countries to not employ highly educated and skilled professional from the region. In South Africa for example, there are a huge number of professionals working mainly in the health and higher education sectors that are from Southern Africa which has benefited the country enormously. However, this hasbeen at the detriment of otherregionalcountrieswho have lost numerous skilled professionals, this prolonging the cycle of underdevelopment and poverty in Southern Africa.

One of the benefits of cross-border migrating in SADC is that it has allowed for the exchange of professionals from other countries, it allows for countries to collaborate on many research and development projects all with the aim of enhancing growth and development in the region (Hansen et al., 2011). However; Hansohm et al. (2005) opine that because countries in the region can't compete in terms of remunerating skilled professionals equally, often some choose to migrate to regional countries where the remuneration is more satisfactory. The Enca (2017) mentions that this trend was unlikely to happen if member states were committed to development. Universities in the region have formed partnerships and exchange programs for skilled academic professionals, all these initiatives are solely aimed at consolidating regional cooperation (Shroder, 2014). Knowledge generated in these projects are often commonly shared among members, hence this has been a major achievement of cross-border migration in the region. These are some of the major achievements which have been directly associated with cross-migration in the SADC, however, cross-border migration has also had its problems which at times have hampered the consolidation of regional cooperation.

Problems associated with cross border migration in SADC-Xenophobia: One of the most serious challenges affecting consolidating the fight against illegal cross-border migration in SADC is Xenophobia (Martin, 2011). Xenophobia is largely associated with South Africa as the country has over the past 5 years, seen more than 6 outbreaks of xenophobic attacks directed at foreign nationals, often these attacks have resulted in serious injuries and death (Nicolson, 2017). While Xenophobia itself may not be a determining 
factor in the cross-border migration process, it does, however, dent South Africa's ability to attract skills, tourism and investments from the region, thus tainting the country's image. The fear of being a victim of Xenophobia might influence one's decision on whether to migrate or not and unfortunately over the past 6 years, xenophobia has been a headache for South African authorities. Xenophobia further shows the poor provision of borders services in the country's borders.

Policies regulating cross-border migration: Kumalo (2013) opines that one of the major issues facing the region is that there is no regionally accepted and adopted policy mechanism that aims at dealing with crossborder migration (especially illegal migration). Williams (2002) mentions that the absence of policies dealing with the management relating to cross-border migration results in certain countries receiving huge inflows in migrants, only to find that if there were regional policies in existence, such could be prevented. According to Song \& Cook (2014) irregular cross-border migration is a challenge for governments in the region as it devours a lot of resources. The South African Department of home affairs mentions that, irregular crossborder migration, creates problems in terms of revenue collection, planning and service provision, undermines the effectiveness of providing protection for foreign nationals in the country and increases the like hood of conflict between local and foreign nationals (Department of Home Affairs, 2017).South Africa has a comprehensive migration policy aimed at regulating migration, however, the policy only concentrates on national regulation, hence there is no policy aimed at regulating and managing cross-border migration in a regional perspective, therefore; cross-border migration will undoubtedly be a continuous phenomenon (Department of Home Affairs, 2017).

Insufficient border control services: Finally, another major challenge in the SADC is that the borders of member states are poorly equipped with the required resources needed to effectively tackle cross-border migration (Brachet et al., 2011). Hansen et al. (2011) mention that before 1960, there were no borders between SADC states and that people could easily move from country to country without any issues. The introduction of borders between SADC states was meant to control the flow of people, but rather this has not been the case especially for countries like South Africa, Botswana and Tanzania, where many cross-border migrants still easily find ways to enter illegally. This is partly due to the fact that border services in many SADC countries including South Africa are still under-resourced, hence many migrants cross at different points, ultimately over stretching border personnel and resources (Khumalo, 2014; Mosieleng, 2013). Chong \& Clark (2017) mention that poor border control also leads to an increase in human trafficking and narcoticsrelated activities taking place. Poor economic growth in SADC has meant that countries have had to decrease operating costs and slash budgets and unfortunately, border patrol services have been one of the victims of such cuts. Mzantsi (2016) states that by the end of 2015, more than a million asylum seekers in South Africa were waiting for their applications to be processed and according to the human rights watch, at the current rate of applications, it would take 20 years to clear the backlog. This makes South Africa one of the top destinations for asylum seekers and further highlighting the need for an effective and inclusive migration policy. While the thrill of migration to another country and living a better life has always been a motivating factor among potential migrants, once successful in their journey, migrants are confronted with many risks such as protection and service provision, discrimination, deportation and the cost and debt incurred while migrating (Kabwe-Segatti, 2008) \& (Fruman et al., 2016). Although these risks are constant challenges of a migrant, cross-border migration in SADC is rife, a clear signal that migrants are willing to risk everything to reach their preferred destination.

Cross border migration in SADC: Future prospects: Undoubtedly the economic disparity among SADC member states will continue to fuel cross-border migration in the region. Countries like South Africa, Botswana, Namibia and Tanzania will in no doubt carry on witnessing a huge number of migrants entering their territories, both legal and illegal migrants. The search for economic prosperity will continue being the defining factor behind cross-border migration in the region.

\section{Methodology}

The study relied on extensively secondary data as a means of collecting relevant and required information. It employed strict textual analysis of the available literature relevant to cross-border migration within Southern Africa. A Qualitative research approach was utilized in the course of this study. The purpose of this approach 
was to put into context of understanding the underlying factors responsible for cross-border migration in Southern Africa and most importantly understand the benefits (if any) that have been accrued by member states, and finally tothoroughlyengageexisting literature to understand and dissect the socioeconomicstructural factors influencing the everincreasing rate ofcross-bordermigration in the SADC. Forrester (2010) asserts that qualitative research uses methods such as participant observation or case studies which result in a narrative descriptive account of a setting or practice. Various scholars have tried to understand the root causes of migration, therefore there are rich sources of information. Though these sources may not comprehensively speak directly to cross border migration within Southern Africa and its overall benefits and problems, they nonetheless offer views on the subject matter which will be utilized to further enrich the study.

Theoretical setting: The movement of people from place to place is motivated or perhaps influenced by many factors. Many scholars from various disciplines have developed numerous theories which ought to explain the migration process from the lens of their respective disciplines. While the constant change in the international political and economic system would undoubtedly push geographers and demographers into providing and adopting new theories that would explain the migration process, it is however, imperative that we utilize the current existing theories to try and better understand global migration as it is a growing phenomenon. The paper will, therefore; highlight some of the theories that have been developed over the years and how they understand and explain the migration process.

Dual market theory: The assumptionof the theory is that migration is influenced by structural demands in developed economies, the theory states that migration is not caused by push factors in sending countries, but rather pull factors in receiving counters (Hugo \& Young, 2008). The theory assumes that developed countries are made up of primary and secondary markets. The primary market is characterised by a huge demand for highly skilled individuals, while the secondary market is labour intensive (Wachter, 1974), thus the requirement of a largely unskilled labour force, dual market theorist assume:

- Governments have the power and resources to influence international migration, but only through major changes in the way which the economy is organized.

- International migration in demand based and begins by employers from developed countries recruiting from the global market.

- The demand for workers from other countries is structurally infused with the needs of the economy of the receiving countries (Tomanek, 2011).

New economics of migration theory: The new economics of migration theory which largely emerged in the 1980 's, views migration as a process or decision taken by a collective, this could be families or groups coming together and deciding to migrate (Brettell\&Hollifield, 2014). Within the premise of this theory, migration is viewed in a cost and benefit situation, if a family would benefit from the migration of a family member, this increases the likelihood that the family member would be advised to migrate (Tomanek, 2011). The theory just like Lee's push/pull and neo classical models uses similar factors to understand the motivating factors behind a family or a group's decision to migrate. An example of migration from the lens of the new economics of migration theory would be when a family sends one of its members to work abroad and then relies on the remittances sent by the family member (Jennissen, 2004), subsequently, remittances sent reduce the likelihood of another family member migrating.

Major assumptions of the theory:

- Migration is a family or collective decision made in order to minimise the risk and maximise income

Social capital theory: According to the social capital theory, connections and networks play a huge role in the migration processes.

The theory assumes that:

- As economies and international migration expand, so do network connections, connections expand so wide that they eventually reach a point where people can migrate to any country without any difficulties 
- Controlling migration is very difficult as migration networks are created outside the country and ultimately occurs irrespective of policies implemented (Byron, 2003).

Less Push/Pull theory: Everest Lee, in his analysis of global migration trends stated that migration was motivated by two factors, push and pull factors. Lee assumed that for people to migrate there has to be something pushing them from their original destination and there has to be something pilling them to their preferred destination (Kivisto \& Faist, 2009).According to this theory, push factors include, lack of economic opportunities, hazard environmental conditions, inadequate safety and security, poor educational and health facilities and political instability, while pull factors include, better working conditions, better salaries, welcoming political climate and opportunities for personal growth (Digby, 2001). However, the theory mentions that between the point of migrating, there are intervening factors that might influence the overall decision to migrate. These factors include the cost associated with migration, distance, family connections, mountains and the restrictive immigration laws in the preferred destination (Weber, 2010). It is undeniably clear that many scholars and theorists from an array of disciplines have over long periods dedicated numerous resources into trying to understand the migration process, hence they have developed theories that they hope will explain and provide a better understanding of the phenomena. It is no doubt that the combination of the assumptions of the above-mentioned theories have in some way manifested themselves within the pretext of cross-border migration in the SADC.

Supporting the assumption of the social capital theory Magidimisha et al. (2018) opine that many illegal immigrants from countries such as Zimbabwe, Mozambique and Lesotho have settled in countries such as South Africa, Botswana and Namibia, where they are involved mostly in the informal sector business, with barber shops and car repair shops being the most prevalent. Dhingra\& Rodriguez (2014) mention that because many have settled in these countries and understand the culture and way of doing business, they may, therefore, influence family members and friends to also migrate because the migrant would have over long periods built the necessary connections and networks in the country having been there for a long time. According to the Centre for Financial Regulation and Inclusion (2012) every year nearly 2 billion Rand leaves South Africa mainly destined for SADC member states, making it that largest remittances market in the regional bloc, thus further reinforcing the assumption of the new economic theory of migration that remittances play a huge role in providing the much needed financial support for the migrants families, hence with steady income a family member may opt not migrate.According to Crush et al. (2005) because of their developed infrastructure networks, developing economies and opportunities for employment, South Africa and Botswana undoubtedly attract a huge number of migrants from the region, with mostly Zimbabweans who are involved in informal sector trading; this notion further highlights the supposition of the dual market theory. Poor rates of economic growth in Zimbabwe have over the years pushed many Zimbabweans to migrate in search of better economic opportunities (Kanyenze, 2011) further highlighting the assumption of Lee's push-pull theory. For the purpose of this study, Lee's push/pull theory will be used as the main theory which will guide the study. This is however, notwithstanding the important assumptions of the other theories which have been discussed as they will be also widely consulted in order to get a different scholarly and disciplinary view of migration.

\section{Results and Discussion}

Undoubtedly, cross-border migration in the SADC has benefited some states more than others. However, illegal migration has also strained government resources in some countries, potentially increasing the possibility of conflict with locals, especially in South Africa, where the periodic outbreaks of Xenophobia have become unpredictable. With this said, there are 4 major findings of the study.

Economic growth and inequality: Magidimisha et al. (2018) mention that the ever-increasing economic disparity will contribute to an increase in cross-border migration in the region, particularly because migrants are in constant search of better economic conditions regionally. The SADC has to collectively work together in order to spur economic growth in the region, hence the economic inequality between countries will be a major factor motivating people to engage in cross-border migration in the region for decades to come. However, while the region grapples to deal with illegal cross-border migration, the increase in remittances flow from South Africa to the region can be viewed as a positive aspect considering the role that they pay 
fighting poverty and their overall contribution to government expenditure in the migrant's home country.Kok (2006) states that cross-border migration is largely influenced by economic conditions in the region, and this can be explained using Wallerstein's world system theory, of the core, semi-periphery and periphery, South Africa in this case, has emerged as the core within the SADC mainly because of the country's industrial development and perceived political and economic stability, South Africa has been seen as preferred destination for migrants.Further highlighting the growing economic disparity within SADC, a study by Garatidye (2014) uncovered that as a result of SADC countries not implementingpolicesmeant to spureconomic growth, many people have engaged in cross-border migration becausesuchopportunitiesarenot present in theirhomecountries. The study concluded that investments and the harmonisation ofregional trade policies were thekey elements needed to reduce cross-border migration. Another study by Ngomane (2010) found that besides economicgrowth, cross border migration in SADC is being fuelled by social networks and family connections, the author opines that these factors will continue influencing cross-bordermigration in the region and concludes that cross-border migration will likely involve numerous families migrating in large numbers going forward. While cross-border migration is on the rise in the region, it is unfortunate that member states have not prioritised the collective development and adoption of economic agreements that would result in inclusive growth regionally, as this would be one of the mechanisms that can be employed to reduce illegal cross-border migration the region.

Policy implementation and coordination: Undoubtedly, it is clear that the magnitude of illegal crossborder migration in the region has reached alarming rates and necessitates for a concise and coordinated response (Bernstein \& Weiner, 2002). As it stands, SADC member states have developed and implemented policies aimed at regulating migration at a national level, however, there is still no clear-cut policy that deals with migration at a regional level. Therefore, the provision of policies to regulate cross-border migration at national level neglect the bigger picture, which is regulating cross-border migration at a regional level. This gap in policy alignment according to Paerregaard (2015) is because some countries are huge senders of migrants rather than receivers; hence they are not to a great extent affected by illegal cross-border migration. A study by Niikondo (2008) found that while regional communities are seen as drivers of regionaland economic cooperation, the SADC however, has not prioritised regional policy implementation to managecross-border migration, another study byNkowani (2005) focusing on economic integration in Southern Africa concluded that there was a need for policy re-alignment between membersof the SADC and a greater consensus on migration relatedissues was needed. A studyNshimbi\&Fioramonti (2014) found that regulating regional migration would be impossible, rather states must strive develop policies that wouldensureregional migration benefits every member state, these policescouldrange from trade, investmentsandeducationaldevelopment. Nonetheless, it is clear that a coordinated and rational response is needed to deal with cross-border migration in the region. While proper management of cross-border migration can yield benefits for receiver countries, the SADC is unfortunately highly characterised by unskilled cross-border migration, hence the continued call for the development of policies that would effectively deal with illegal cross-border migration in SADC.

Crime/Human Trafficking and HIV: Increase in the numbers engaging in cross-border migration in the region, coupled with poor border policies will undoubtedly increase migration related crime such as human trafficking and narcotics smuggling. Roth (2017) states that countries characterised by poor border services are prime targets for human trafficking syndicates as there is poor control, therefore doing illegal activities becomes rather simple. Song \& Cook (2014) also state that border patrol guards working in such regions are easy targets for bribery, because of poor resources to carry out their work and the low pay means accepting bribes becomes a way of life in such situations. Anichet al. (2014) mention that within the SADC, only Lesotho has ratified the convention of the protection of the rights of migrants and members of their families. Surprisingly, though, South Africa as the largest receipts of migrants in the regionbut has not ratified this protocol, implying that cross-border migration cannot be stopped or reduced. This undeniably complicates the fight against illegal cross-border migration but even worse it invites crime syndicates whicheffect social cohesion and development in the region. Another big threat facingthe SADC is the growing infection rate of $\mathrm{HIV}$ and as countries in the region seeker closer integration and cooperation; undoubtedly the spread of HIV will have devastating effects on socio-economic development. A study by the Abrahámová (2008) mentioned that countries with insufficientresources to ensure effective border control were morelikely to receive more 
illegal migrants, and the increase in illegal cross-border migration may result in the increase in the spread of communicable diseases (Gushulak \& MacPherson, 2004).

The SADC has the highest levels of HIV prevalence in the world, many countries in the region are already grappling to try and reduce the spread of the virus. Some of the factors that are contributing to the spread of HIV in the region include: high rates of labour migration between countries, as people seek better working conditions and standards of living, alcoholism, illiteracy, poverty and economic inequalities. According to the world health organization, in 2015, it was found that 36.7 million were living with HIV, with SADC accounting for 40 percent of those people, meaning 14640000 people in the region are living with HIV and that figure is expected to rise significantly in the near future. A report by Kotzé\&Marauhn (2014) mentioned that the poor management of borders in the region means people can move unregulated, hence further increasing the likelihood of spreading the disease. In the region, South Africa has the highest number of people living with HIV. Observer (2017) mentions that because of the non-existence of a regionally accepted policy regulating migration, HIV will likely spread in the region as people are in constant movement in search of better opportunities. There are many issues that need to be resolved in order for the SADC to fully reap the benefits that come with cross-border migration, and these issues have to be solved collectively hence every member has to have a say how policies are developed and implemented.

\section{Conclusion and Recommendations}

It is undoubtedly that cross-border migration is rife within the SADC region and it has been characterised by a huge number of illegal migrants to countries such as South Africa, Botswana and Tanzania mainly for economic reasons, further straining government resources in receiving countries. Not every member in the SADC is equally affected by migration some are affected more than others, hence the delay in finding a common policy to deal with cross-border migration the region. To reduce cross-border migration, the following suggestions may be may be piloted:

Instituting a free movement policy: In light of the above discussion on cross-border migration in Southern Africa, it is evident that the migration process is unlikely to decrease in the region, hence the possibility of regional countries coming together and agreeing to formulate a regional policy that will aid in the management of the migration process. While the policy will require extensive discussions and consultation, it will however, go a long way in ensuring that cross-border migration will be handled at a regional level. Czaika\& De Haas (2013) support the above statement and allude that considering the benefits that migration can sometimes bring, its regulation at a regional level may enable its benefits to be equally beneficial.

Strengthening of border services: Undoubtedly, not all countries in the region experience the same rate of immigration, mainly because of the different socio-economic structures that make up SADC member states. For countries experiencing high rates of cross-border immigration, one solution would be to invest in resource provision for border services, although this will not deter determined individualsfrom engaging in cross-border migration, it will nonetheless better aid border immigration services in better performing their duties and will reduce the number of people engaging in cross-border migration to certain countries. However, with SADC countries experiencing poor rates of economic growth, the provision of additional resources for border services seems way off; ultimately, this may impede border services from performing their duties commendably.

Punitive measures for corrupt officials: Undeniably, developing nations, because of underdevelopment, poverty and rampant maladministration, many officials especially those stationed at border posts are involved in corrupt activities, where in South Africa especially, many are implicated in bribery scandals. This undoubtedly calls for harsh measures to be taken against anyonefound committing corrupt activities in the borders. Cross-border crime has been on the steady increase in SADC, and many officials have been implicated in these crimes, hence the provision of harsher laws will clearly send strong signal about the region's goal of rooting out corruption.

Harsher laws for employing illegal migrants: Globally, companies prefer employing migrants instead of locals, mainly because migrants are perceived to care little about the salary they receive, rather the little that 
they get is pivotal for the survival of the migrantsfamily back home. SADC member states should jointly agree on policies punishing those found to be employing illegal migrants as this alone acts as a pull factor towards other migrants. A fine or penalty should be levied against the employer as this would ensure that employers are in compliance with regional laws. While these suggestions may go a long way in reducing the flow of cross-border migrants in the region, it is imperative that one notes that migration itself is a complex phenomenon and it is virtually impossible to totally eradicate or stop cross-border migration. Therefore, the SADC needs to invest in resources and cooperation in order to implement policies that would help reduce the flow of cross-border migration.

\section{References}

Abrahámová, N. (2008). Immigration Policy in Britain Since 1962 (Doctoral dissertation), Masaryk University. Czech Republic

Andersen, E. \& Lindsnaes, B. (2007). Towards new global strategies: public goods and human rights. MartinusNijhoff Publishers. Leiden

Anich, R., Crush, J., Melde, S. \& Oucho J. (2014). A new perspective on human mobility in the South (Vol. 3). Springer. Berlin

Bastia, T. (2013). Migration and inequality (Vol. 100). Routledge. Abingdon

Beaton, M., Cerovic, M., Galdamez, M., Hadzi-Vaskov, M., Loyola, F., Koczan, Z., Lissovolik, M., Martijn, M. \&Ustyugova, M. (2017). Migration and Remittances in Latin America and the Caribbean: Engines of Growth and Macroeconomic Stabilizers? International Monetary Fund. Washington

Bernstein, A. \& Weiner, M. (2002). Migration and refugee policies: an overview. A\&C Black. London

Boampong, M. (2014). Is migration a solution for youth unemployment? Retrievedfromhttps://www.weforum.org

Brachet, J., Gabrielli, L., Gaibazzi, P., Palomares, E., Pian, A., Poutignat, P., Quiminal, C., Schapendonk, J., Spire, A., Streiff-Fénart, J. \& Timera, M. (2011). The challenge of the threshold: Border closures and migration movements in Africa. Lexington Books. Lanham

Bradshaw, Y. \&Ndegwa, S. (2000). The uncertain promise of Southern Africa.Indiana University Press. Indiana Brettell, C. \&Hollifield, J. (2014). Migration theory: Talking across disciplines. Routledge. New York

Brynard, P. (2011). Policies and poverty in Southern Africa. University of Pretoria, Pretoria

Byron, R. (2003). Retrenchment and regeneration in rural Newfoundland.University of Toronto Press. Toronto

Centre for Financial Regulation and Inclusion. (2012). The South Africa-SADC remittance channel. Retrieved: http://cenfri.org

Chen, Q. (2016). Globalization and transnational academic mobility: The experiences of Chinese academic returnees. Springer. Berlin

Chong, N. \& Clark, J. (2017). Human Trafficking: A Complex Phenomenon of Globalization and Vulnerability. Routledge. Abingdon

Council on Higher Education. (2012). Higher Education Data: Participation. Retrieved from: http://www.che.ac.za.

Cox, A. (2016). Gigaba: SA can benefit by welcoming migrants. Retrieved from: https://www.iol.co.za.

Crush, J. \& Dodson, B. (2017). Harnessing Migration for Inclusive Growth and Development in Southern Africa.Southern African Migration Programme.Topocopy. Cape Town

Crush, J. (2017). Informal migrant entrepreneurship and inclusive growth in South Africa, Zimbabwe and Mozambique.Southern African Migration Programme. Waterloo

Crush, J., Williams, V.\&Pebedy, S. (2005). Migration in Southern Africa.Global Commission on International Migration. Geneva

Czaika, M. \& De Haas, H. (2013). The effectiveness of immigration policies. Population and Development Review, 39(3), 487-508.

Department of Home Affairs. (2017). White paper on international migration for South Africa.Retrieved from: www.dha.gov.za.

DeTemple, J. (2007). Globalization and Development in Latin America.Journal of Latin American and Caribbean Anthropology, 12(1), 266-268.

Dhingra, P. \& Rodriguez, R. (2014). Asian America: Sociological and Interdisciplinary Perspectives. John Wiley \& Sons. Hoboken 
Digby, B. (2001). Global Challenges.Heinemann Educational Press. Oxford

Enca. (2017). Zuma calls for collective approach in developing SADC. Retrieved from: https://www.enca.com.

Forrester, M. (2010). Doing qualitative research in psychology: A practical guide. Sage.California

Furman, R., Epps, D.\&Lamphear, G. (2016). Detaining the Immigrant Other: Global and Transnational Issues.Oxford University Press. Oxford

Garatidye, S. (2014). An exploration of the experiences of Zimbabwean women informal cross-border traders at the Zimbabwean/South African BeitBridge border post. (Doctoral dissertation) University of Cape Town, South Africa

Gasa, N. (2007). Women in South African History: They remove boulders and cross rivers. HSRC Press. Pretoria

Gibert, S.\& Chiumia, S. (2016). FACTSHEET: Where do South Africa's international migrants come from? Retrieved from: https://africacheck.org.

Godsäter, A. (2016). Civil Society Regionalization in Southern Africa: The Cases of Trade and HIV/AIDS. Routledge. Abingdon

Grinin, L., Ilyin, V., Herrmann, P.\&Korotayev, A. (2016). Globalistics and globalization studies: Global Transformations and Global Future. Uchitel. Volgograd

Gushulak, B. \& MacPherson, D. (2004). Globalization of infectious diseases: the impact of migration. Clinical Infectious Diseases, 38(12), 1742-1748.

Hahn, K. (2005). Towards a SADC area of higher education. NEPRU, Namibian Economic Policy Research Unit. Windhoek

Halvorsen, T. \& Vale, P. (2016). One World, Many Knowledges: Regional experiences and cross-regional links in higher education. African Minds. Somerset West

Hansen, R., Koehler, J. \& Money, J. (2011). Migration, nation states, and international cooperation (Vol. 23). Routledge. Abingdon

Hansohm, D., Hodge, J. \&Ndulo, M. (2005). State of Trade in Services and Service Trade Reform in Southern Africa (No. 31). NEPRU Research Report.

Hugo, G. \& Young, S. (2008). Labour mobility in the Asia-Pacific region: dynamics, issues and a New APEC agenda. Institute of Southeast Asian Studies. Singapore

Human Rights Watch. (1998). Prohibited Persons: Abuse of Undocumented Migrants, Asylum-seekers, and Refugees in South Africa.Human Rights Watch. New York

International Organization for Migration. (2006). World Migration 2005 Costs and Benefits of International Migration (Vol. 3). Academic Foundation.

International Organization for Migration. (2008). World migration 2008: Managing labour mobility in the evolving global economy (Vol. 4). International Organization for Migration. Geneva

Jalilian, H. (2012). Costs and Benefits of Cross-country Labour Migration in the GMS (Vol. 2). Institute of Southeast Asian Studies. Singapore

Jennissen, R. (2004). Macro-economic determinants of international migration in Europe.Rozenberg Publishers. Amsterdam

Kabwe-Segatti, A. (2008). Migration in post-apartheid South Africa: Challenges and questions to policymakers. Agencefrançaise de développement, Département de la recherche. Paris

Kanyenze, G. (2011). Beyond the enclave: Towards a pro-poor and inclusive development strategy for Zimbabwe. Weacer Press. Harare.

Keating, M. (2004). Gender, Development, and Trade. Oxfam. Oxford

Khumalo, S. (2014). Unlocking South African cross-border transport challenges: a case study of Beitbridge border post. University of Pretoria. Pretoria

Kivisto, P. \&Faist, T. (2009). Beyond a border: The causes and consequences of contemporary immigration. Sage. California

Kok, P. (2006). Migration in South and Southern Africa: dynamics and determinants. HSRC Press. Pretoria

Kothari, C. (2004). Research methodology: Methods and techniques. New Age International. New Delhi

Kotzé, L. \&Marauhn, T. (2014). Transboundary Governance of Biodiversity. Martinus Nijhoff Publishers. Leiden

Kumalo, S. (2013). SADC Does Not Have a Regional Migration Policy. Retrieved from: http://www.publicnewshub.com

Leerkes, A. (2009). Illegal residence and public safety in the Netherlands.Amsterdam University Press. Amsterdam 
Lemarchand, G. \&Schneegans, S. (2014). Mapping research and innovation in the Republic of Zimbabwe.UNESCO. Paris

Leonard, T. (2013). Encyclopaedia of the developing world. Routledge. Abingdon

Lippoldt, D. (2012). Policy Priorities for International Trade and Jobs (pp. 125-142). OECD. Paris

Lucas, R. (2005). International migration and economic development: Lessons from low-income countries. Edward Elgar Publishing. Cheltenham

Magidimisha, H., Khalema, N., Chipungu, L., Chirimambowa, T. \&Chimedza, T. (2018). Crisis, Identity and Migration in Post-Colonial Southern Africa.Springer International Publishing. Berlin

Mapuva, J. \& Muyengwa-Mapuva, L. (2014). The SADC regional bloc: What challenges and prospects for regional integration? Law, Democracy and Development, 18, 22-36.

Markowitz, C. (2017). What SADC needs to do to make the most of regional value chains? Retrieved from: https://www.businesslive.co.za

Martin, G. (2011). Feature: illegal migration and the impact of cross border crime. Retrieved from: http://www.defenceweb.co.za.

Matlosa, K. (2001). Migration and development in Southern Africa: policy reflections. SAPES Books. Harare

Mattes, R. Crush, J. \& Richmond, W. (2000). The brain gain: skilled migrants and immigration policy in postapartheid South Africa (No. 20). Southern African Migration Project. Cape Town

Mosieleng, T. (2013). Southern African Development Community (SADC) and the question of illegal immigration: A case study of South Africa (Doctoral dissertation). University of North West, South Africa

Mzantsi, S. (2016). SA's 'alarming' asylum seeker backlog. Retrieved from: https://www.iol.co.za.

Nicolson, G. (2017). Xenophobia: Attacks, now a march. Retrieved from: https://www.dailymaverick.co.za

Niikondo, A. (2008). Regional integration in the Southern African Development Community (SADC) (Doctoral dissertation). University of Namibia, Namibia

Nkowani, Z.P. (2005). Regional integration and the dualism of economic and social policy: The dilemma for foreign direct investment and trade over occupational health and safety: a policy re-alignment for the Southern African Development Community [SADC] (Doctoral dissertation) University of Salford, Manchester

Ngomane, T. (2010). The socio-economic impact of migration in South Africa: a case study of illegal Zimbabweans in Polokwane Municipality in the Limpopo Province (Doctoral dissertation). University of Limpopo, South Africa

Nshimbi, C.\&Fioramonti, L. (2014). The will to integrate: South Africa's responses to regional migration from the SADC region. African Development Review, 26(S1), 52-63.

Nshimbi, C. \&Moyo, I. (2017). Migration, Cross-Border Trade and Development in Africa: Exploring the Role of Non-State Actors in the SADC Region. Springer. Berlin

Observer, S. (2017). HIV/AIDS situation a mess in SADC.Retrieved from: https://www.pressreader.com.

Odén, B. (1996). Southern African futures: Critical factors for regional development in Southern Africa (Vol. 7). Nordic Africa Institute. Uppsala

Oderth, R. (2002). Migration and brain drain: the case of Malawi. Springer Nature. Victoria

Odoom, F. (2010). The State of African Cities 2008: A framework for addressing urban challenges in Africa. United Nation Settlement Programme. Nairobi

Omelaniuk, I. (2012). Global perspectives on migration and development: GFMD Puerto Vallarta and beyond (Vol. 1). Springer Science \& Business Media. Berlin

Orpen, G. (2015). Remittances from South Africa to SADC.Retrieved from: http://slideplayer.com.

Oucho, J. (2005). Internal Displacement of Population in the SADC Region: An Overview. In Seminar on International Displacement in the Southern African Development Community (SADC) Region.Retrieved from: https://warwick.ac.uk

Paerregaard, K. (2015). Return to sender: the moral economy of Peru's migrant remittances. Univ of California Press. California

Pécoud, A. \&Guchteneire, P. (2007). Migration without borders: essays on the free movement of people. Berghahn Books. New York

Peters, W. (2010). The Quest for an African Economic Community: Regional Integration and Its Role in Achieving African Unity-the Case of SADC (Vol. 591). Peter Lang. Bern

Plender, R. (1988). International migration law (Vol. 2). MartinusNijhoff Publishers. Leiden 
Powell, R.\& Powell, J. (2016). AQA Economics Student Guide 2: The national economy in a global context. Bookpoint. Abingdon

Robinson, S. (2007). Mozambique and Regional Integration in Southern Africa.Falmer. Sussex

Roth, M. (2017). Global organized crime: A 21st century approach. Taylor \& Francis. London

Sabates-Wheeler, R. \& Feldman, R. (2011). Migration and social protection: Claiming social rights beyond borders. Springer. Berlin

Saurombe, A. (2013). The European Union as a model for regional integration in the Southern African Development Community: a selective institutional comparative analysis. Law, Democracy \& Development, 17, 457.

Schiantarelli, F. (2005). Global economic prospects 2006: economic implications of remittances and migration. The World Bank. Washington

Shroder, J. (2014). Hazards, risks, and disasters in society. Elsevier. Amsterdam

Solé, C., Parella, S., Martí, T. \& Nita, S. (2016). Impact of Circular Migration on Human, Political and Civil Rights: A Global Perspective (Vol. 12). Springer. Berlin

Song, J. \& Cook, A. (2014). Irregular migration and human security in East Asia.Routledge. Abingdon

Speckman, M. \&Mandew, M. (2014). Perspectives on Student Affairs in South Africa.African Minds. Somerset West

Tomanek, A. (2011). International Migration Theories. Retrieved from: http://understandingmigration.blogspot.co.za

Van Rensburg, R. (2016). SA looks to clamp down on 'economic migrants. Retrieved from: http://citypress.news24.com.

Wachter, M. (1974). Primary and secondary labor markets: a critique of the dual approach. Brookings Papers on Economic Activity, 3, 637-693.

Weber, L. (2010). Demographic Change and Economic growth: Simulations on growth models. Springer. Berlin

Wellman, E. \& Landau, L. (2015). South Africa's tough lessons on Migrant Retrieved from: http://foreignpolicy.com

Williams, V. (2002). An overview of migration in the SADC region. In Seminar on Regional Integration, Migration and Poverty.Retrieved from: https://sarpn.org

Willimans, V \& Crush, J. (2005). Harmonisation if migration policies in SADC states. Idasa. Capetwon

Wisner, B., Toulmin, C. \& Chitiga, R. (2005). Towards a new map of Africa. Routledge. Abingdon

Wohlmuth, K., Gutowski, A., Kandil, M., Knedlik, T. \&Uzor, O. (2014). Macroeconomic Policy Formation in Africa-General Issues (Vol. 16). LIT VerlagMünster. Munster

Zuberi, T., Sibanda, A. \& Udjo, E.O. (2016). The Demography of South Africa.Routledge. Abingdon 